\title{
O corpo e suas representações na tessitura identitária umbandista
}

\author{
The body and its representations in the umbandist identity tessiture
}

Marcelo Máximo Purificação ${ }^{1 *}$, Elisângela Maura Catarino²

\begin{abstract}
RESUMO
Este texto é produzido no âmbito da disciplina Pedagogia do Corpo, do Programa de Pós-Graduação em Educação (Doutorado) da Universidade Luterana do Brasil - ULBRA, com aproximação com o projeto de tese - que tem como objeto as identidades umbandistas juvenis no contexto escolar. Objetiva-se discutir sobre o corpo e suas representações no processo de construção identitária de jovens umbandistas. O corpo, visto a partir da perspectiva religiosa, é uma poderosa forma de comunicação por onde perpassa o espetáculo do ethos, materializando em gestos e em formas os orixás - divindades cultuadas nas religiões de matrizes africanas, por meio do processo da incorporação. A incorporação ou possessão é, segundo Ortiz (1999, p.71), o elemento central do culto, permitindo a descida dos espíritos do reino da luz, da corte de Aruanda, que cavalgam a montaria da qual eles são senhores. Para Carlos de Ogum (s/d), quando o atabaque fala, a alma escuta e o corpo responde. O corpo, como elemento desse cenário, se configura numa importante fonte dialógica que possibilita abarcar vários tipos de experiências dentro da categoria do êxtase (LEWIS, 2003).
\end{abstract}

Palavras-chave: Corpo; Umbanda; Movimento; Identidade e Representações.

\begin{abstract}
This text is produced in the scope of the discipline Pedagogy of the Body, of the Post-Graduate Program in Education (Doctorate) of the Lutheran University of Brazil - ULBRA, in an approximation with the thesis project - which has as its object the juvenile Umbanda identities in the school context. The objective is to discuss about the body and its representations in the process of identity construction of young Umbanda people. The body, seen from a religious perspective, is a powerful form of communication through which the spectacle of ethos permeates, materializing in gestures and forms the orixás - deities worshiped in African-based religions, through the process of incorporation. Incorporation or possession is, according to Ortiz (1999, p.71), the central element of the cult, allowing the descent of the spirits of the kingdom of light, from the court of Aruanda, who ride the mount of which they are masters. For Carlos de Ogum (undated), when the atabaque speaks, the soul listens and the body responds. The body, as an element of this scenario, configures itself in an important dialogic source that makes it possible to encompass various types of experiences within the category of ecstasy (LEWIS, 2003).
\end{abstract}

\footnotetext{
${ }^{1}$ Universidade Estadual de Mato Grosso do Sul (UEMS).

*E-mail: marcelo.ueg@gmail.com

${ }^{2}$ Fundação Integrada Municipal de Ensino Superior (FIMES/UNIFIMES)
} 


\section{INTRODUÇÃO}

A umbanda insere-se no contexto das religiões afro-brasileiras, considerada, no universo religioso, como uma religião recente. No entanto, é um fenômeno religioso que resume muito bem o povo brasileiro. Muitos autores direcionam a umbanda como resultado de um processo de trajetória histórica do contexto brasileiro, enraizado em hábitos culturais que elevam o desenvolvimento social, cultural e espiritual do indivíduo no imaginário coletivo, entre os quais citamos Luzia Negrão (1993), que apresenta a religião da Umbanda como interconexão entre os apelos de suas raízes sombrias e os atrativos legitimadores da adoção de princípios éticos cristãos. Embora pouco racionalizada e postulando uma visão de mundo predominantemente encantada, ela foi se tornando cada vez mais moralizada, principalmente sob a influência do ideal kardecista de caridade (NEGRÃO, 1993).

Ao abordar esse contexto de umbanda com a tríade: corpo, cultura e pluralismo religioso, surge a ideia do fenômeno religioso. Do ponto de vista do fenômeno religioso, sabemos que essa dimensão é plural e que os sujeitos, nela imersos, são atravessados por instituições religiosas, em que crenças, ações, comportamentos, mitos, ritos, etc. (SILVA, 2004). Ao observar esses sujeitos e seus corpos, entendemos que os sentidos que atribuímos ao corpo, nesse cenário de pluralismo religioso, "ocorrem nos processos de significação cultural”. (SOUZA, 2001).

São diversas as manifestações de corpos em transe mediúnico destacadas e narradas em trabalhos científicos, das quais citamos a pesquisa desenvolvida por Pellicciari (2008) na Pós-graduação em Ciências (USP), em que os médiuns falam dos desdobramentos vividos na incorporação, que é a experiência extática de seu corpo. Os colaboradores da referida pesquisa expõem as diferentes sensações oriundas do corpo, tais como: "visão, intuições, audição e toda uma série de sentidos envolvidos neste processo" (p.17).

Como médium desenvolvido e atuante na umbanda, complemento ao informar que durante o processo de incorporação ocorre o acoplamento de auras (do médium e da entidade). Este processo é como se houvesse uma interconexão dos chakras médium 
(centro de energia, localizado no corpo) com os chakras da entidade. Trabalho com três negros velhos: quando eles são incorporados, meu corpo toma os contornos de cada um deles. Para além das diferentes curvaturas do corpo em cada um deles, a voz, o olhar, o passo, os gestos, etc. indicam que são pessoas diferentes que habitam o mesmo corpo. Outro exemplo que posso citar da minha experiência mediúnica é a incorporação de erês (divindades infantis/ crianças), que quando estão em terra, ou seja, incorporados ao médium, se comportam como crianças - falam, andam e se comportam como crianças. Dito isso, concordamos com Brumana (1984) e Pellicciari (2008), que "o corpo não pode ser ignorado nos estudos que investigam a relação entre as pessoas e as manifestações divinas" (p. 20).

\section{Tessituras das identidades nas representações umbandistas}

As identidades da Umbanda, vistas pelas lentes da cultura, estão ancoradas nos arquétipos do povo brasileiro. Eles têm sinais que simbolizam o pluralismo que existe no contexto social do nosso país. Para Prandi (2005), as representações do caboclo no índio, do preto velho - no sábio e velho escravo -, do boiadeiro - que representa o camponês -, etc. são elementos balizadores dessa pluralidade, marcadores da Umbanda como religião genuinamente brasileira. Essas identidades, expressas nos rostos do povo brasileiros, transformam seus corpos em lugares onde "são examinadas as questões sociais e humanas do contato direto com as possibilidades espirituais por meio do transe da possessão, Pellicciari (2008, p. 21).

Nas concepções de Pólvora (2001), o corpo e seus movimentos se traduzem em conhecimentos que são repassados entre culturas e gerações. Por isso, afirma a autora, ele "porta as tradições religiosas", seja pela oralidade ou pela corporeidade. Os corpos em movimentos perpassados pela religiosidade "configuram as manifestações como um lugar privilegiado para o estudo da cultura" Pellicciari (2008, p. 24). Na linha dessas ideias, Montero (1994), salienta que pensar o corpo inserindo na cultura, não significa reduzi-lo a mero objeto, mas, ao contrário, apresentá-lo como matéria vivida. E vai mais adiante, especificando que:

(...) o universo religioso brasileiro, sobretudo em sua vertente mais marcada pelas tradições indígenas e africanas, em que a possessão religiosa está no centro do rito, 
veicula um conjunto de valores que tende a produzir uma identidade social ${ }^{3}$. (MONTERO, 1994, 76).

A identidade social umbandista ganha vida nos terreiros, local em que o ritual acontece em meio as gingas dos corpos e solavancos advindos do acoplamento do corpo do médium às entidades. $\mathrm{O}$ branco adorna as vestimentas marcando de representações e significados aos corpos e aos ritos. O terreiro é o local onde as identidades umbandistas se manifestam livremente, onde os corpos expressam os trejeitos nas mãos e nos gestos que identificam cada entidade. Local onde os corpos livres transitam sem o julgo da indiferença e sem as marcas da intolerância, dois termos que colocam em crise as identidades umbandistas.

Com isso, é importante dizer que assumir-se como umbandista é um ato político. Digo, por ser a Umbanda uma religião de matriz africana, portanto, de minoria - também conhecida como religião de negro, todo esse posicionamento da Umbanda no contexto social de negritude, faz com que ela seja intercruzada e marcada pelo símbolo da diferença, que sinaliza as identidades negras desde os primórdios do negro no Brasil. Historicamente falando, o Brasil é conhecido como um país católico. Hoje, segundo o site de informações da Globo G1 (13/01/2020) $50 \%$ da população do Brasil são de autodeclarados católicos, $31 \%$ de evangélicos, $10 \%$ que não se posicionaram, 3\% espíritas e $2 \%$ das religiões de matriz africana (Candomblé e Umbanda). A construção da identidade religiosa no Brasil atualmente tem muito dessa base histórica, que traz um processo de desqualificação da identidade do povo negro - não só pelos marcadores de seus corpos - que envolve o cabelo, a cor da pele, os traços físicos em si, mas, enquanto cultura, enquanto religião, enquanto forma de ser e de agir.

Agora imagine: se o indivíduo cresce ouvindo falar mal da Umbanda, que ser umbandista é feio; que a Umbanda é uma religião que que faz o mal; que o umbandista é macumbeiro, é feiticeiro. O indivíduo que vê seus templos e seus artefatos sagrados serem destruídos pela violência e pela ira da intolerância, por que ele vai querer se identificar

\footnotetext{
${ }^{3}$ Conceito cunhado por Henri Tajfel (1983), "como aquela parcela do autoconceito dum indivíduo que deriva de seu conhecimento da sua pertença a um grupo (ou grupos) social, juntamente com o significado emocional e de valor associado àquela pertença" (p. 290).

${ }^{4}$ Disponível em: https://g1.globo.com/politica/noticia/2020/01/13/50percent-dos-brasileiros-saocatolicos-31 percent-evangelicos-e-10percent-nao-tem-religiao-diz-datafolha.ghtml. Acessado em $16 / 12 / 2020$.
} 
com essa religião? Por que deixará visível em seus corpos elementos simbólicos que o identifique como membro/ participante desse movimento? Principalmente para aqueles que quem ainda não têm conhecimento, não têm pauta de lutas, que não têm ainda uma construção teórica acerca da temática delineada. Por isso, a importância de pesquisa nessa linha, que ao meu ver, acaba sendo uma forma de resistência, pois traz para o campo dialógico reflexões sobre atual situação dos corpos negros e das religiões no Brasil, dando voz às religiões tidas como de minorias. Como afirma Hall, "a identidade somente se torna uma questão quando está em crise, quando algo que se supõe como fixo, coerente e estável é deslocado pela experiência da dúvida e da incerteza" (1999, p. 9).

\section{O corpo e sua comunicação na Umbanda}

Meu corpo é um corpo umbandista, portanto, um corpo livre que vibra e ginga ao som dos atabaques. Um corpo aparelho do bem e da caridade, radiado pela energia das entidades que me escolheram como portal. (PURIFICAÇÃO)

Figura 1 - Saudação do altar

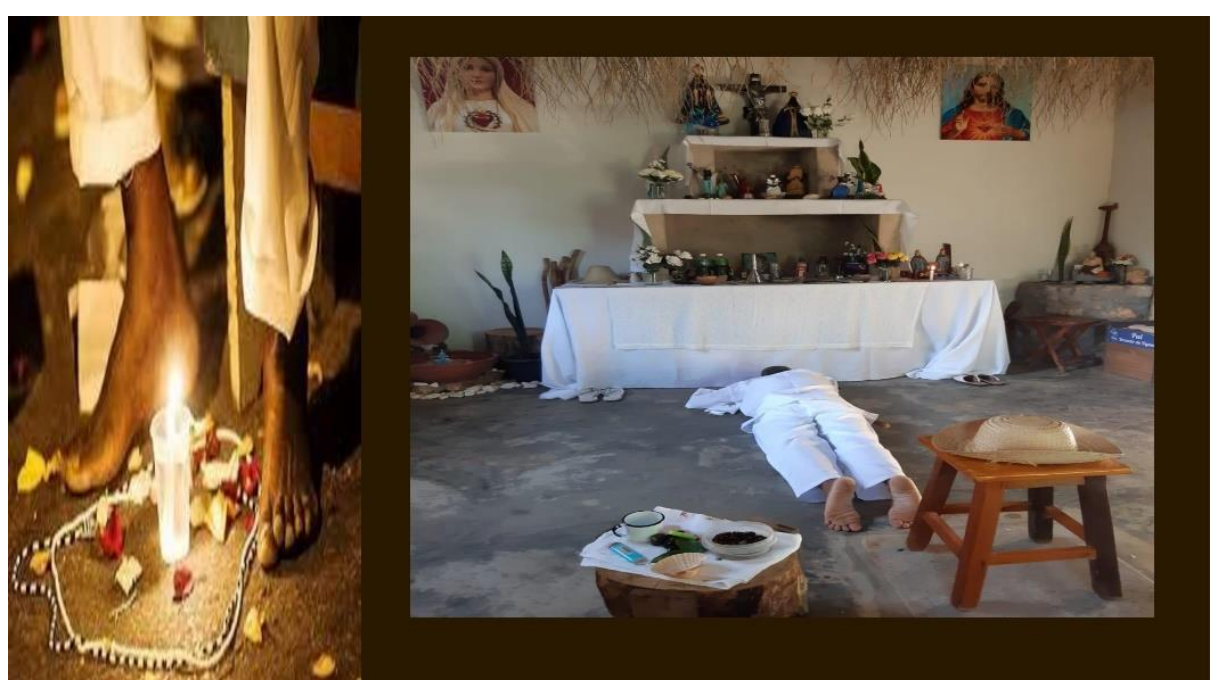

Fonte: arquivo pessoal/ 2020

O corpo e seu movimento são ferramentas essenciais para o ritual de umbanda, por meio do qual a comunicação midiática, a música, a dança e o swing são reconhecidos, afirma Rouget (1980). Para Laban (1971/1878, p. 102), o corpo é a fonte da qual deve vir a perfeição, e a última área do movimento é a compreensão daquela parte da vida interior do homem da qual fluem o movimento e a ação. Do ponto de vista de Dantas (1999), o corpo sucumbe ao impulso do movimento pela dança, permitindo que se mova e se 
transforme. Ele atravessa o espaço, brinca com o tempo, brinca com forças físicas e leis, diverte com seu peso, provoca dinâmicas inusitadas (p. 28). O corpo na umbanda, [...], "além de ser o centro das atenções, tornou-se um discurso visual e não verbal sobre quem somos. É, portanto, um lugar de construção identitária”, afirma Isse (2003, p. 43). Nesse contexto, é importante entender que o corpo de Umbanda é sempre um desfecho temporário e inacabado. Ele é atravessado, formado por categorias sociais, como: classe, geração, raça/ etnia, gênero e sexualidade, que podem ser entendidos de diferentes formas, disse Dornelles. (2012, p. 189).

Muitos são os artefatos que atravessam os corpos umbandistas. Entre eles, estão as guias, que sem sombra de dúvidas, são importantes fontes de comunicação quando intercruzadas aos corpos umbandistas. As guias de Umbanda, conhecidas por muitos como fios de contas, são preparadas por pessoas específicas de acordo com as normas da casa, podendo atingir um número grande de cores, diretamente relacionadas aos Orixás. Um médium de Umbanda carrega em seu corpo esses marcadores, que representam sua filiação no santo, sua trajetória e seu desenvolvimento na religião. As guias, suas cores e representações estarão sempre presentes nas giras, nos trabalhos, nas festas de santos e etc. As guias e seus formatos podem expressar a inter-relação de lateralidade (direito/ esquerdo), de gênero (homem/ mulher), de tempo (presente/ passado). Geralmente as guias utilizadas pelos pais/ mães-de-santo costumam ser uma espécie de brajá ${ }^{5}$, que trazem as cores do Orixá de Cabeça ou de búzios com as cores do Guia de Cabeça (Caboclo ou Preto-Velho), fortalecendo a ideia do pluralismo da Umbanda (BARBOSA JÚNIOR, 2014, 385).

Para melhor ilustrar sobre os corpos das entidades na Umbanda, trazemos nessa sessão informações e concepções de (BARBOSA e BAIRRÃO, 2008, p. 229-230), sobre os movimentos dos médiuns quando incorporados com entidades, como: Pretos velhos, Caboclos, Boiadeiros, Marinheiros e Crianças.

\footnotetext{
${ }^{5}$ Brajá é o fio-de-contas usado por Babalawos. Enciclopédia livre. Acessado em 15/12/2020.
} 
Figura 2 - Preto Velho

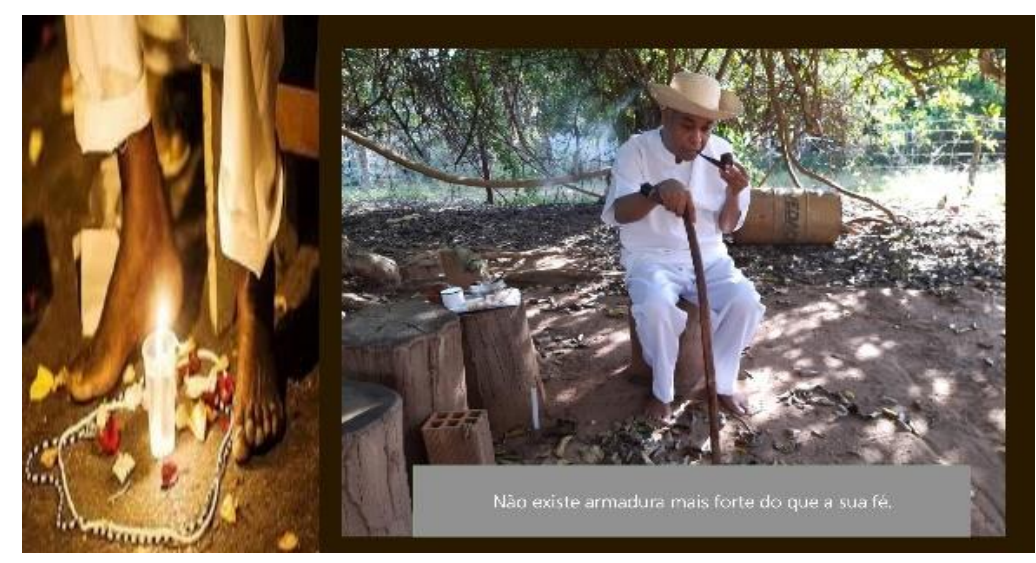

Fonte: Arquivo: pessoal/ 2020

Pretos velhos - "Os pretos-velhos movimentam-se tal e qual um homem muito velho e encurvado, que treme as pernas e frequentemente apoia os braços ou um braço na coxa, deixando o outro atrás das costas, parcialmente parado. Caminham com os pés inteiramente apoiados no chão, mantêm a cabeça baixa e estalam os dedos de uma das mãos. Andam vagarosamente e logo se sentam, parecendo cansados" (BARBOSA e BAIRRÃO, 2008, p. 229).

Figura 3 - Caboclos

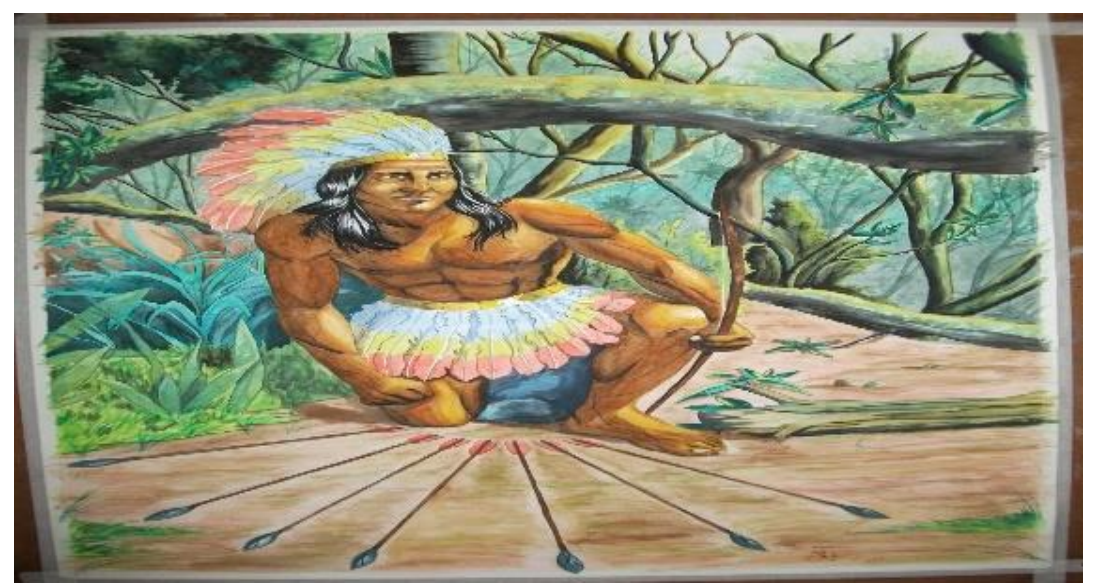

Fonte: Google.com, 2021.

Caboclos - "Cruza os braços batendo no peito com força, mantém as mãos fechadas, ou semifechadas, fazendo a forma de um "L" com o dedo indicador e o polegar esticados. Costuma gritar durante esse movimento, porém há grandes variações desse movimento inicial. Alguns caboclos apenas batem com os braços cruzados no peito, outros batem e encostam-nos no chão e alguns fazem o movimento de lançar uma flecha, 
como se estivessem esticando a corda de um arco". (BARBOSA e BAIRRÃO, 2008, p. 230).

Figura 4 - Boiadeiro

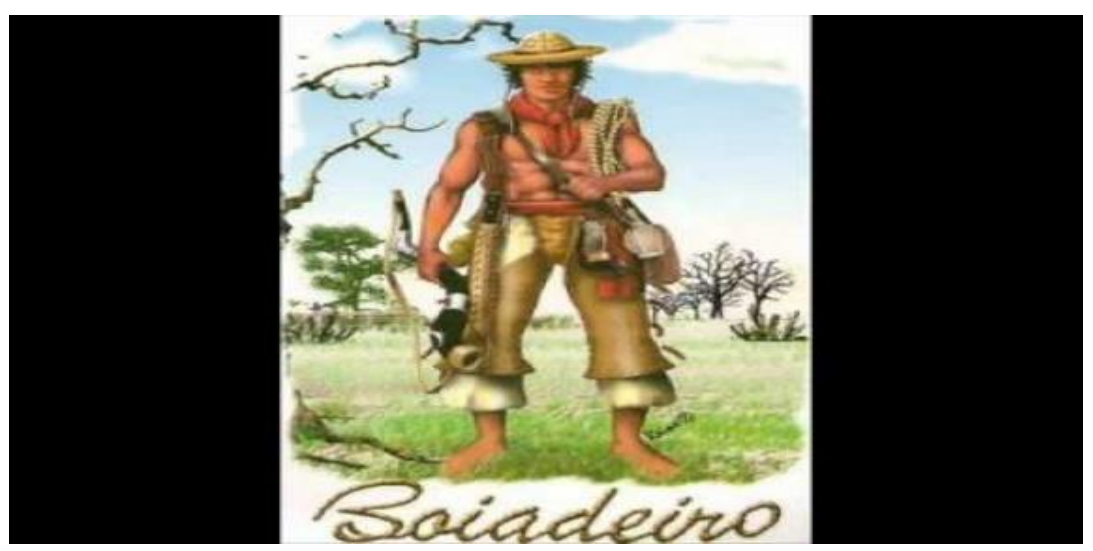

Fonte: Google.com, 2021.

Boiadeiro - "A mão que faz o movimento geralmente o faz acima da cabeça, enquanto o outro braço pode manter-se apoiado na cintura ou solto, enquanto a mão estala os dedos. Esse movimento com os braços, característico do boiadeiro, apresenta o fator de movimento peso pouco firme, já que mostra tensão muscular e resistência ao peso, mas sem dar a sensação de um movimento extremamente tenso" ". (BARBOSA e BAIRRÃO, 2008, p. 229).

Figura 5 - Marinheiros

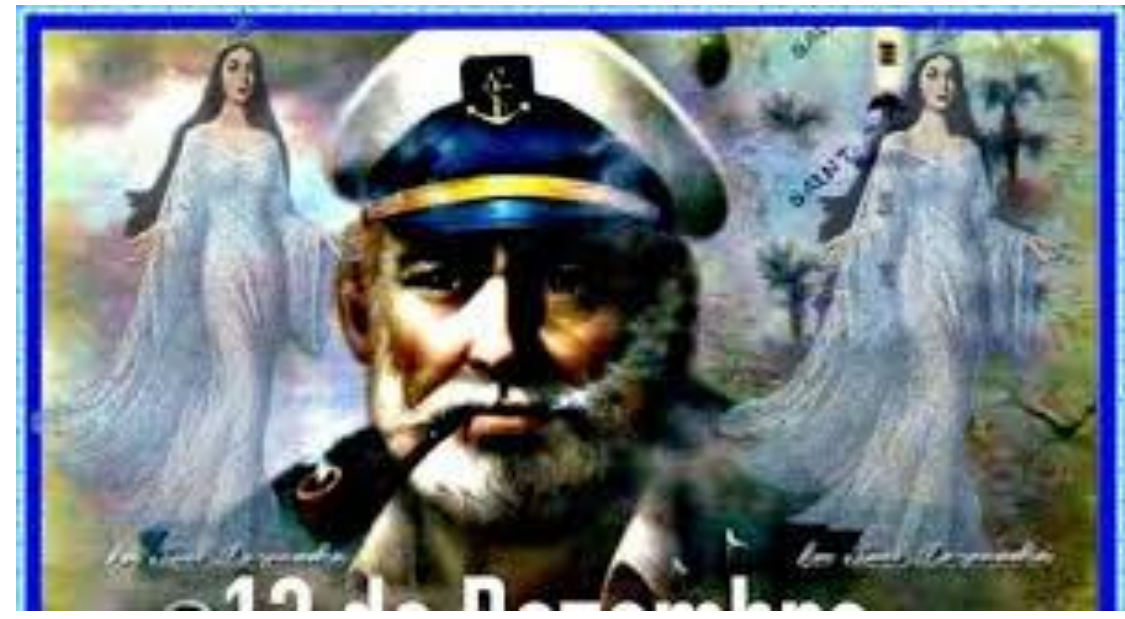

Fonte: Google.com, 2021. 
Marinheiros -"Suas pernas podem tanto aparecer com os joelhos flexionados, o que passa a sensação de um corpo sem tonicidade, sem firmeza, quanto com estes esticados, passando a impressão de falsa firmeza, visto este estiramento denunciar certa falta de controle. O tronco e a cabeça dos marinheiros parecem, na maior parte das vezes, acompanharem o andar cambaleante ou o precederem, visto ser o deslocamento deles que cria a necessidade de movimentação das pernas" ". (BARBOSA e BAIRRÃO, 2008, p. 229).

Figura 6 - Crianças

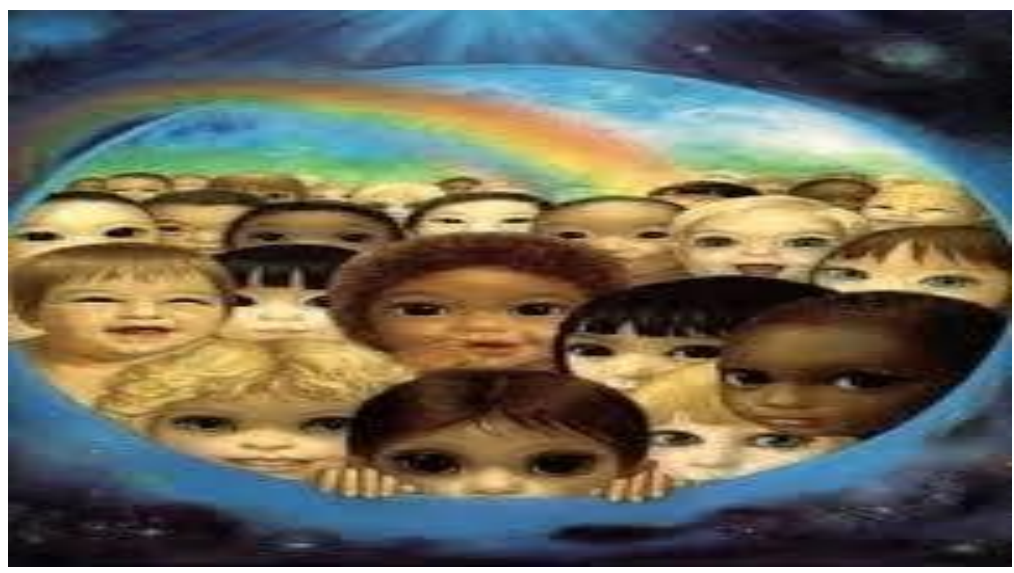

Fonte: Google.com, 2021.

Crianças - "Quando as crianças dançam, batem palmas e pulam descoordenadamente em relação à música e com vivacidade, passando a impressão de alegria e excitação transbordantes do corpo. Geralmente não ficam em pé por muito tempo. Ficam sentadas e arrastam o corpo para movimentar-se". ". (BARBOSA e BAIRRÃO, 2008, p. 230).

As descrições acima apresentam corpos umbandistas desenvolvendo diferentes ações/ comportamentos, dando vida ao que chamamos de arquétipo, ou seja, a forma teatral que as entidades utilizam ao se manifestarem. As descrições dos autores mostram detalhes das entidades umbandistas que se materializam nos corpos dos médiuns quando incorporados. As entidades umbandistas assumem os rostos do povo simples do Brasil, o que as tornam cheias de significações e representações sociais e culturais. 


\section{Considerações finais}

Apesar do discurso da diversidade cultural, de crenças e identidades, ainda nos deparamos com a intolerância religiosa fortemente velada em nossa sociedade. O corpo umbandista no Brasil carrega o jugo de estereótipos que rasuram identidades, quando não as invisibilizam. O corpo umbandista é marcado pelo preconceito e pela violência, que historicamente atravessa corpos diferentes ou identificados como de minorias. Por isso, optei em desenvolver nesse novo doutoramento uma pesquisa sobre "Identidade Umbandista Juvenis em contexto escolar", pois acredito que é chegada a hora de incorporar o currículo cultural no currículo escolar. Se o fizermos, estaremos a contribuir para uma sociedade mais justa e inclusiva, com potencial para analisar, problematizar e refletir sobre os diferentes corpos, suas múltiplas identidades no quotidiano, valorizandoo e dando-lhe voz. Importa, assim, no quadro dos direitos humanos, repensar estas questões, possibilitando que os corpos jovens que povoam as escolas, possam aprender de outro modo, através do confronto e desconstrução de saberes e/ou práticas que apelem a uma maior conscientização e valorização de diversas culturas em presença, contribuindo para a formação de cidadãos e cidadãs mais atentos, responsáveis e críticos.

\section{REFERÊNCIAS}

BARBOSA JUNIOR, Ademir. O livro essencial de Umbanda. São Paulo: Universo dos livros, 2014.

BARBOSA, M. K.; BAIRRÃO, J. F. M.H. Análise do Movimento em Rituais Umbandistas. Psic.: Teor. e Pesq., Brasília, 2008, Vol. 24 n. 2, pp. 225-233

BRUMANA, F. G. El Cuerpo Sagrado: acerca de las analises de fenômenos de posessión religiosa. In: Reis: Revista Española de Investigaciones Sociológicas. N. 34, p. 161-193, (1984).

DANTAS, M. Dança: o enigma do movimento. Porto Alegre: Ed. Universidade, f126, 1999 
HALL, S. Identidade cultural na pós-modernidade. 3. ed. Rio de Janeiro: DP\&A, 1999.

ISSE, Silvane Fensterseifer; SANTIN, Silvino - Orientador. Corpo e feminilidade: um estudo realizado com meninas adolescentes no contexto da educação física escolar. 2003. 161 p. f. Dissertação (Mestrado em Educação Física) - Escola de Educação Física, Universidade Federal do Rio Grande do Sul, Porto Alegre, 2003.

LABAN, R. (1978). Domínio do Movimento. São Paulo: Summus Editorial (Trabalho original publicado em 1971)

Lewis, I, Ecstatic Religion: A Study of Shamanism and Spirit Possession (3a ed.). London/New York: Routledge. (Trabalho original publicado em 1971), 2003.

MONTERO, P. Magia, nacionalidade e sujeitos políticos. In: Revista Brasileira de Ciências Sociais. São Paulo, 1994.

NEGRÃO, Luzias Nogueira. Umbanda, entre a cruz e a encruzilhada. Revista social USP. São Paulo. 1993.

ORTIZ, Renato. A morte branca do feiticeiro negro: umbanda e sociedade brasileira. São Paulo: Brasiliense, 1999.

POLLICCIARI, F. S. Estudos da significância do corpo na umbanda: limites e possibilidades de aplicabilidade de alguns conceitos lacanianos. Dissertação de Mestrado. Programa de Pós-Graduação em Psicologia, USP, 2008.

PÓLVORA, J. B. O corpo batuqueiro: uma expressão religiosa afro-brasileira. In: LEAL, O. F (Org.) Corpo e Significado. Porto Alegre - RS: Ed. Universidade, $2^{\mathrm{a}}$ ed. P. 123-135, 2001.

PRANDI, R. Segredos guardados: orixás na alma brasileira. São Paulo: Companhia das letras, 2008, $336 \mathrm{p}$.

Rouget, G. La Musique et La Transe: esquisse d'une théorie générale des relations de la musique et de la possession. Paris: Gallimard, 1980. 
SILVA, Eliane Moura da. Religião, Diversidade e Valores culturais: conceitos teóricos e a educação para a Cidadania. In: Revista de Estudos da Religião, n. 2. São Paulo: PUC, 2004. p. 1-14.

SOUZA, Nádia Geisa Silveira de. Que corpo é esse? O corpo na família, mídia e saúde...Tese de Doutorado apresentada ao Programa de Pós-Graduação em Bioquímica da UFRGS, 2001. Disponível em: https://www.lume.ufrgs.br/bitstream/handle/10183/1817/000308959.pdf?sequence=1. Acessado em 15, dez. 2020. 